\title{
Psychological Inflexibility Moderates Stress and Loneliness in Depression Among Indonesian College Students During the COVID-19 Pandemic
}

\section{Annisa Mega Radyani, Gracia Hanna Indra, and Imelda Ika Dian Oriza*}

Department of Clinical Psychology, Faculty of Psychology, University of Indonesia, West Java, Indonesia

\section{ORCID}

Imelda Ika Dian Oriza; https://orcid.org/0000-0003-0790-6393; https://orcid.org/0000-00023628-0759

Corresponding Author: Imelda Ika Dian Oriza; email:

imelda.ika@ui.ac.id

Dates

Published 28 January 2022

Publishing services provided by

Knowledge $\mathrm{E}$

(c) Annisa Mega Radyani et

al. This article is distributed

under the terms of the

Commons Attribution License,

which permits unrestricted use and redistribution provided that the original author and source are credited.

Selection and Peer-review under the responsibility of the ICoPsy Conference Committee.
Abstract. The COVID-19 pandemic has had a tremendous impact on college students' mental health. Recent studies have found increased perceived stress and loneliness during the pandemic, which are significant risk factors for depression. However, few researchers have specifically discussed the particular factors that can exacerbate the impact of these risk factors on depression. Psychological inflexibility is said to have an important role in facilitating the development of mental health problems. The current study explored the role of psychological inflexibility in moderating perceived stress and loneliness in depression during the COVID-19 pandemic. A cross-sectional study using an online survey was conducted to assess college students' sociodemographic information, perceived stress, loneliness, and depression during the COVID-19 pandemic. A total of 941 Indonesian college students (age range $=18-39$ years old, 74\% female) were analyzed using correlation analysis and SPSS macro PROCESS moderation analysis. Several sociodemographic factors such as age, marital status, previous mental health record, education level, perceived impact of COVID-19, income, and financial status were significantly associated with depression and psychological inflexibility, and were thus controlled as covariates. As predicted, higher psychological inflexibility was associated with higher perceived stress, loneliness, and depression. Results showed psychological inflexibility elevated the effect of both perceived stress and loneliness on the depression level. These findings support previous literature regarding the significant role of psychological inflexibility in moderating the development of depression, especially during the COVID-19 pandemic. Based on the findings, it is recommended that alternative interventions are implemented to inhibit the development of depression by decreasing psychological inflexibility, while considering sociodemographic factors.

Keywords: OVID-19 pandemic, college student, depression, psychological Inflexibility, perceived stress, loneliness

\section{G OPEN ACCESS}




\section{Introduction}

On March 11, 2020, the World Health Organization declared the outbreak of COVID-19 as a global pandemic [1]. The pandemic affected over 200 countries globally, posing enormous various challenges to the entire population [2]. The pandemic has brought not only the risk of death from infection, but also an increased risk of psychological distress [3], [4]. Young people aged 18-24 years are the most affected population in regards to mental health during COVID-19 pandemic [5]. A previous study found young adults in the U.S. were having clinically elevated levels of distress and PTSD symptoms during the initial weeks of the COVID-19 pandemic [6].

In non-pandemic situations, individuals in typical college-aged populations (18 to 24 years old) have the highest prevalence of mental health disorders [7]. Facing college demands while undergoing a developmental transition from adolescence to adulthood have made them the most vulnerable group to develop mental illness [8-11]. With the addition of pandemic circumstances, college students may have elevated psychiatric risk [12], [13], [6]. The closure of schools due to quarantine and physical distancing policies forced students to adjust to remote learning activities and, in the case of incoming students, have their start of study delayed by their prospective universities [3], [6]. Other adverse consequences such as financial instability, imbalance of educational resources between urban and rural areas, confirmed COVID-19 cases within family or relatives, and lack of social connection caused by physical distancing have also emerged [14], [3], [6], [15].. These challenges could become new significant mental health risk factors for college students [3], [16], [15]. Furthermore, the challenges and pressures were not only felt by undergraduate students but master and Ph.D. students as well [17-19].

A similar pattern was identified in Indonesian youths. Since March 15, 2020, Indonesia has been implementing physical distancing and stay-at-home regulation to manage the spread of the COVID-19, thus forcing schools and universities to close [20]. A national survey in Indonesia ( $\mathrm{N}=4010)$ during the fifth month of the COVID-19 pandemic reported $65 \%$ anxiety, $62 \%$ depression, and $75 \%$ traumatic symptom [21]. Furthermore, the report also showed young people (aged between 17 to 29 years old) as the highest number of mental health problems [21]. Another survey $(\mathrm{N}=600)$ further illustrated students' struggle during online learning, where $53 \%$ of them reported feeling pressured to stay productive, 33\% feeling stressed over lack of concentration, and 25\% feeling easily irritated, angry, or upset [22]. These were all common features of mental health problems [22]. Unfortunately, there is a dearth of literature that specifically illustrates the mental 
health condition of Indonesian college students during the COVID-19 pandemic. Hence, the current study will provide more data in these regards.

Initial research in other countries suggested the increased prevalence of depression among young people has become one primary concern during the COVID-19 pandemic [16], [23], [15]. Depression is a type of mood disorder, characterized by persistent sadness, lack of interest or pleasure in previously rewarding or enjoyable activities, and may affect a person's ability to function and live a rewarding life [24]. A study on undergraduate and graduate students in the US shows that the prevalence of depression is two times higher in 2020 than in the previous year [17]. These mental health problems can harm their academic functioning, adjustment to their environment, and quality of life [7].

Certain potential risk factors for depression among college students had likely emerged throughout the COVID-19 pandemic [3], [15]. With many changes in their college activities and daily routines, students who have higher vulnerability to everyday stressors may have an elevated perceived stress level during the pandemic. Loneliness has also been identified as a risk factor for depression and may be particularly prevalent during the pandemic [25], [6], [26], [23]. Feeling disengaged from social connection due to social distancing and isolation may make one feel lonely and vulnerable, especially among college students [27], [6], [28], [29]. The current study then will focus on exploring both perceived stress and loneliness as two predictors of depression.

Therefore, it is crucial to identify specific constructs that may hinder students from handling COVID-19 pandemic challenges effectively. One construct that is said to play a critical role in aggravating non-adaptive behavior during difficult circumstances is psychological inflexibility [30]. The present study will mainly explore the role of psychological inflexibility in moderating the perceived stress and loneliness's impact on depression among Indonesian college students.

\subsection{Present Study}

To the best of our knowledge, there are currently no studies exploring the association between psychological inflexibility, perceived stress, loneliness, and depression, particularly in the context of college students during the COVID-19 pandemic. Perceived stress and loneliness are related to the cognitive discrepancies between what is desired and their actual experiences. Without good psychological flexibility, this gap may cause them to struggle or ruminate with their thoughts over the undesired experience. The tendency of individuals to have rigid dominance of the psychological process makes it 
difficult for them to adjust to the current pandemic situations, thus increasing the risk of depression.

Moderation analysis is needed to see how psychological inflexibility could alter the association between perceived stress and loneliness toward depression. This knowledge can add further evidence whether psychological inflexibility can be the target intervention for people with high perceived stress or loneliness level and prevent the development of depressive symptoms during pandemic. Therefore, the research intends to explore how psychological inflexibility $(\mathrm{M})$ moderates the association between perceived stress (IV 1) and loneliness (IV 2) on depression (DV) in the context of college students during the COVID-19 pandemic. The present study will examine three hypotheses: (1) The association between psychological inflexibility with COVID-19 risk factors, particularly perceived stress and loneliness; (2) The role of psychological inflexibility moderates the relationship between perceived stress during the COVID-19 pandemic and depression; (3) The role of psychological inflexibility moderates the relationship between loneliness during the COVID-19 pandemic and depression.

\section{Literature Review}

\section{COVID-19 risk factors: Perceived Stress and Loneliness on Depression}

Perceived stress is a predictor of depressive symptoms and is considered a potentially modifiable risk factor [31-34]. It can be defined as a state occurring in response to events or demands that exceed an individual's perceived ability to cope [32], [35]. Stress exposure may happen in various contexts, including physical, social, cultural, biological, and health [32]. The stress process is very subjective and depends on the individuals' perceptions of environmental demands or events [31], [35]. Therefore, the rapid changes and needs amid the COVID-19 pandemic may impact college students' perceived stress levels and heighten their mental illness risk [6]. Prior researchers had evidence where perceived stress could predict the severity of depressive symptoms [31], [33], [34].

The cognitive discrepancy model defined loneliness as a discrepancy between the desired quality of the relationship and actual experiences [28], [36], [26]. The significant changes in the way people interact during the COVID-19 pandemic (i.e., virtual meetings only, maintaining physical distance) may cause difficulties in creating a new and close relationship, thus worsening students' feelings of loneliness. An elevated level of loneliness resulting from quarantine has been reported [37], [23]. Loneliness also had been 
known as a significant predictor of depression [6], especially among college students [27], [28], [26], [29].

Nevertheless, sociodemographic factors such as age, sex, socioeconomic status, and educational background are likely to remain notable determinants of student's mental health during the pandemic [6], [5]. Therefore, the present study will also explore the sociodemographic factors that may be linked to the mental health outcome, particularly depression.

\section{Psychological Inflexibility and Depression}

Psychological flexibility is a construct proposed by Hayes and his colleagues [30], which involves the ability to exercise attentional control even in situations that are complex, evocative, or intensely social in nature. The construct is described as a set of processes that determine how well individuals recognize and adapt to situational demands by engaging in adaptive behaviors to pursue personally meaningful (valuesdriven) longer-term outcomes [38], [39], [30]. It is the core model of human functioning and behavior changes targeted by several contextual behavioral interventions [30], [40], including Acceptance and Commitment Therapy (ACT).

In contrast, the excessive control of a person's thoughts, feelings, and emotions, with a tendency to avoid unpleasant or challenging experiences at the expense of effective and valued actions, is related to psychological inflexibility [41-42]. Psychological inflexibility is defined as the rigid dominance of psychological reactions, over chosen values and contingencies, in guiding action [43-44]. It is characterized by inflexible attention, disruption of chosen values, inaction or impulsivity, attachment to a conceptualized self, cognitive fusion, and experiential avoidance [30].

Researchers have found psychological inflexibility to be related to many mental health problems, such as worry, depression, anxiety, trauma, and stress in various contexts [43-44], [30], [41], [16], [10], [42]. Moreover, psychological inflexibility has been proposed to facilitate the development of mental health problems [20], including depression and anxiety [45], trauma [46], suicide behavior [47], and other psychopathological symptoms [48], [41]. The high association between psychological inflexibility and mental health problem was also observed among college students [43], [49], [10]. Recent studies show that psychological inflexibility can facilitate the association between psychological distress and academic procrastination [44] and sleep problems [49] among college students. Furthermore, students with greater psychological inflexibility reported having lower college self-efficacy [50]. Being inflexible may make them less adaptive to new challenges as they have difficulties using personal resources, resulting in a higher risk of academic failure and depression. 
Limited studies have found the link between psychological inflexibility and depression during the COVID-19 pandemic in the general population[39]-[40], [16]. At the same time, the data indicate the possible crucial role of psychological inflexibility as a target for prevention or intervention efforts to treat mental health problems caused by the pandemic.

\section{Method}

\subsection{Participant}

A total of 1028 college students participated in the present cross-sectional study. We assessed the sociodemographic data, perceived stress, loneliness, depression, and psychological flexibility of Indonesian college students worldwide during the COVID-19 outbreak. The data was gathered between June 18, 2020, and July 6, 2020, using online questionnaires and took approximately $15-20$ minutes for the participants to complete. A convenience sample of college students was contacted to participate in the study using various social network groups. The questionnaire was advertised as research to explore the psychological impact of the COVID-19 pandemic on Indonesian college students. After completing the study, participants were given access to 'a self-care guidebook during COVID-19 pandemic' written by a faculty lecturer who specialized in health psychology and well-being. Study inclusion criteria included: 1) Indonesian nationality currently enrolled as a student in a Local or Overseas University, (2) Age between 18 - 40 years old. We assessed Indonesian students in various countries during the COVID-19 pandemic while considering the similarities in physical distancing, stay-athome, and closure of university regulations in every country. We received and omitted responses that failed to meet the study inclusion criteria and subsequently conducted preliminary data analysis. The initial screening resulted in 941 responses to be used for final analysis.

\subsection{Measures}

Sociodemographic. Sociodemographic questionnaire was used to collect general data on age, gender ( 1 = "Female", 2 = "Male"), marital status ( 1 = "Single", 2 = "Married", 3 = "Married with child", 4 = "Divorce"), perception of financial status (1 = "Not enough", 2 = "Enough", 3 = "More than enough"), and previous mental health record ( 1 = "Yes", 2 = "No", 3 = Maybe, haven't been diagnosed officially). We also obtained information related 
to their current educational background, such as university background ( 1 = "Local University", 2 = "Overseas University"), program level (1 = "Undergraduate Student", 2 = "Master Student", 3 = "PhD Student"), a field of study (1 = "Science, Engineering, Health Sciences", 2 = "Social Sciences, Humanities, and Law", 3 = "Linguistic", 4 = "Art") and their COVID-19 pandemic experience such as perceived impact of COVID-19 (rating scale from $0=$ "Not at all" to 5 = "Very Affected"), duration of impact ( $1=$ " 1 month", 2 = "2 month", 3 = "3 month", and so on), place of residence during the COVID-19 pandemic (1 = "Live with parents", 2 = "Live with spouse and children ", 3 = "Live alone at Boarding house / Dormitory / Apartment", 4 = "Live with roommate at Boarding house / Dormitory / Apartment"; 5 = "Live with relative"), income stability (1 = "Yes", 2 = "No"), and whether they have relative or acquaintance with COVID-19 diagnosis (1 = "Yes", 2 = "No"). Qualitative data was also collected to give us more details on some variables (country of study, source of income).

Perceived Stress. We used the Perceived Stress Scale [31] to measure the degree to which life situations from the past month are considered stressful. It consisted of 10 items with a 5-point scale in which participants rated their symptoms between 0 (never) to 4 (very often). The total score ranged from 0 to 40 , with higher scores indicating higher perceived stress. The total score classification is 0-13 for Low Stress, 14-26 for Moderate Stress, 27-40 for High Perceived Stress. We used the Indonesian version of the questionnaire [51] which has good reliability (Cronbach $\alpha=.81$ ) and was validated by an expert and congruent validity test.

Loneliness. We assessed loneliness using the 20-item UCLA Loneliness Scale Version 3 [52] to measure an individual's subjective feelings of loneliness as well as feelings of social isolation. Participants rated their symptoms on a 4-point scale ranging from 1 (Never) to 4 (Often). The total score ranged from 20 to 80, with higher scores indicating greater loneliness. The score's categorization was $20-34$ for mild loneliness, 35 - 48 for moderate loneliness, and over 48 for severe loneliness [27], [53]. The present study used the Indonesian version [54] which has acceptable reliability (Cronbach $\alpha=$ 0.77).

Psychological Inflexibility. The Acceptance and Action Questionnaire-II [43] measured psychological inflexibility, the opposite of psychological flexibility. The tools measured the individual's inability to fully contact the present moment and thoughts and feelings, persisting in or changing behavior to pursue personal goals and values [48]. It contained seven items, using a 7-point scale from 1 (Never true) to 7 (always true). The total score ranged from 7 to 49 , with higher scores indicating greater psychological 
inflexibility. The average mean score in a clinical population was 28.3 , while in a nonclinical population was 18.51 . The cut-off score of 24-28 may indicate a clinically relevant level of distress [43]. The present study used the Indonesian version of the questionnaire [55] which has excellent reliability (Cronbach $\alpha=0.918$ ) and is validated by an expert and comprehensibility test.

Depression. The Patient Health Questionnaire [56] was a brief self-report measure assessing depression symptoms from the past two weeks based on the DSM-IV criteria. The participants responded to the nine items where they rated their symptoms on a 4-point scale, ranging from 0 (not at all) to 3 (almost every day). The total score ranges from 0 to 27, with the score of 16 and above represented depression severity score at which further assessment is recommended. The severity classification for total score: None-Minimal (0 - 4), Mild (5-9), Moderate (10-14), Moderately Severe (15-19), Severe (20-27). The internal reliability of PHQ-9 was excellent, with Cronbach $\alpha=$ 0.89. The published Indonesian versions of the questionnaires were used (available at www.phqscreeners.com).

\subsection{Data Analysis}

Analyses were carried out using IBM SPSS 25 and SPSS Macro PROCESS by Hayes version 3.5 [57]. First, descriptive statistics and correlation analysis were conducted to examine associations between sociodemographic factors and the outcome variable. We used point-biserial correlation and zero-order correlation (Pearson's $r$ and Spearman's Rho) to explore the association among variables. We also used an independent sample t-test and ANOVA for categorical variables to explore the within-group difference. Factors significantly associated with depression were controlled as covariates in the corresponding moderation analysis. For sociodemographic factors, responses to some items were converted to categorical and continuous variables.

Next, to examine the moderating role of psychological inflexibility in the link between perceived stress and loneliness on depression, two simple moderation analyses were executed using Process Model 1 [57], one for each independent variable through 1000 bootstrapped samples. Process model 1 was used to test the conditional effect by estimating the impact of Independent Variables on Dependent Variable at certain points along with the moderator and testing if the effect is significant [16]). The variable is considered a significant moderator if the 95\% confidence intervals (Cl's) for the interaction (IV x Moderator) did not include zero. Johnson-Neyman analysis was implemented to 
investigate the pattern of effects as both the predictor and moderator are continuous variables [57], [16].

\section{Results and Discussion}

\subsection{Preliminary analysis}

Preliminary data analysis was performed to identify duplicate cases, missing values, and multivariate outliers within primary variables of interest. After eliminating data that violates these provisions, the total data used for the final analysis was 941 . All scales have good internal reliability, with Cronbach's $\alpha$ range between $0.85-0.91$. Table A.1 summarizes descriptive data and correlation for each sociodemographic variable with depression and psychological inflexibility. We separated the sociodemographic variables into three sections: general, university-related, and COVID-19 related.

In our study (See Table A.1), the participants' age range was 18-39, with the predominant gender being female (74\%) and relationship status being single (85\%). More than $54.4 \%$ had not experienced any significant mental health problem, 32.7\% potentially facing some mental health issues, and $7.2 \%$ had been diagnosed professionally. The majority of participants (67\%) were studying at various local universities in Indonesia, while others (33\%) at overseas, with the highest number of responses collected from England (6.2\%), Japan (4.7\%), Netherland (3.8\%), Germany (3.4\%), China (3\%). Participants consisted of $52 \%$ undergraduate students, $43 \%$ master students, and $5 \%$ Ph.D. students. Most participants (47\%) studied social sciences, humanities, and law, followed by science, engineering, and health sciences field (42.5\%). In regards to COVID-19 related variables, the average score $(M)$ for the perceived impact of COVID-19 was 3.77 $(S D=1.08)$, with a duration of impact range between $0-6$ months. A total of $7 \%$ reported having a family or relative diagnosed with COVID-19. The majority of participants lived at their parent's house (58\%). In regards to financial status, most of them had steady income (81\%) earned from various sources: $75.7 \%$ from family or relatives, $40 \%$ from scholarships, and $27.8 \%$ from personal savings. More than half of them (54\%) perceived their financial status as enough.

Several sociodemographic factors were found significantly associated with depression and psychological inflexibility (See Table A.1). The increase in age was associated with lower depression and psychological inflexibility. For marital status, the lowest depression and psychological inflexibility levels were found in students who have been married with children, whereas the highest was found in students who were still single. 
As expected, students who had or might have had previous mental health issues showed higher depression and psychological inflexibility scores compared to none.

There is a significant association between education level with depression and psychological inflexibility. Interestingly, undergraduate students showed higher depression and inflexibility levels compared to the other levels. The undergraduate students showed moderate levels of depression $(M=10.57, S D=.26)$ and clinically relevant psychological inflexibility $(M=31.41, S D=8.95)$ compared to Master and Ph.D. degrees which showed mild depression and lower psychological inflexibility. There is also a significant association between the perceived impact of COVID-19 with depression and psychological inflexibility, although the duration of impact itself did not show any correlation with both variables. Those who did not have a steady income and assessed their current salary as insufficient during the pandemic showed the highest depression and psychological inflexibility level.

Finally, significantly associated variables were included as covariates in the moderation analysis to control potentially confounding effects. These variables are age, marital status, previous mental health record, education level, perceived impact of COVID-19, income, and financial status.

\subsection{Primary Variables: Descriptive and correlations}

We used descriptive and correlation analysis to explore the correlations between all the primary variables. The current study found that $43.89 \%(n=413)$ students had a clinical symptom of depression (exceeded the cut-off score at which further assessment is recommended), with the overall mean score shows around the moderate level of depression $(M=9.39, S D=5.77)$. Almost $60 \%$ of participants $(59.82 \%, \mathrm{n}=563$ ) shows concerning psychological inflexibility level $(M=28.86, S D=9.19)$. Overall, participants of the study had moderate level of perceived stress $(M=20.90, S D=6.65)$, moderate level of loneliness $(M=40.91, S D=10.32$ ). The description and correlation between primary variables are displayed in Table B.1. A strong positive association $(p<.001)$ was observed between psychological inflexibility and all predictors (perceived stress and loneliness) and the outcome (depression).

\subsection{Moderation Analysis}

To investigate how psychological inflexibility moderates the relationship between (Model 1) perceived stress and depression and (Model 2) loneliness and depression, 
two sample moderation analyses were conducted using Hayes PROCESS Ver 3.5. Consistent with the hypotheses, the interaction between both predictors (perceived stress and loneliness) and psychological inflexibility were significant in depression. Both models illustrated higher psychological inflexibility mitigates the effects of predictors on depression.

Model 1 shows the conditional effect of perceived stress on depression symptoms was significant and the effect of psychological inflexibility on depression symptoms. The interaction $(b=.011, \mathrm{t}(930)=6.162, p<.001, C / 95 \%[.007, .014])$ explained $58.9 \%$ of the variance of depression symptom with the interactions uniquely explained $2 \%$ of the variance. Model 2 shows the conditional effect of loneliness on depression symptoms was significant and the effect of psychological inflexibility on depression. The interaction term $(b=.006, \mathrm{t}(930)=4.65, p<.001, C / 95 \%[.003, .008])$ explained $55 \%$ of the variance of depression symptom with the interactions uniquely explained $1 \%$ of the variance. Furthermore, Johnson-Neyman plots show that all levels (low, average, high) of the perceived stress and loneliness are significantly related to depression $(p<.001)$ at all levels of psychological inflexibility. Overall, these results indicate that psychological inflexibility has great significance in moderating both the effect of perceived stress and loneliness on depression, even after controlling the covariates.DiscussionThe present study highlights the possible association between psychological inflexibility with perceived stress, loneliness, and depression. Psychological inflexibility may significantly intensify both risk factors' detrimental effect on depression, even after controlling the sociodemographic factors. As the moderation model explained around 55\% of the variance in depression, we may conclude that the magnitude of the interaction is clinically meaningful [58], [16]. The higher level of psychological inflexibility, the higher impact of perceived stress and loneliness on the severity of depression. The results are consistent with prior research [48], [41], [45], indicating that psychological inflexibility may significantly facilitate the development of distress in various contexts [59, [16], including COVID-19 pandemic.

Being psychologically inflexible means the difficulties to fully contact with the present moment, avoid the unwanted inner experience, and lack of commitment to purse and live personal values [44]. Our data illustrated more than $57 \%$ of the participants had high psychological inflexibility. This raises a serious concern as psychological inflexibility is a problematic coping strategy that may hinder people from taking effective action [39], [44], especially during difficult situations. Students with high psychological inflexibility may face many problems when adapting to unfamiliar circumstances during COVID-19 pandemic. The tendency to have excessive control over their thoughts and 
emotions (Bond et al., 2011), may worsen their negative experience and escalate the risk of developing a severe mental illness, including depression.Our data illustrated a positive association between psychological inflexibility and depression [43[, [41], [40], [6]. The individuals with high psychological inflexibility may have difficulties in emotion/behavior regulation process, in which the primary characteristics of depression. Moreover, more than $43 \%$ of our participants had a clinical symptom of depression, similar to a recent study conducted in the United States [6]. This number added more evidence of depression becoming a severe problem for college students [62]. Perceived stress and loneliness, which acted as our main risk factors in the current study, were also found to impact the severity of depression significantly.

This study further explained how the relationships between perceived stress and depression might be elevated when students have psychological inflexibility. Individuals who had high perceived stress found their lives unpredictable, uncontrollable, and overwhelming [31]. The school's closure and rapid transition to online learning during the pandemic may be appraised as very difficult and challenging for college students. While trying to adapt to quarantine life, they were pressured to face developmental transition, which poses many challenges, including academic pressure, increased independence, self-exploration, and attending to various work or family responsibilities [8]-[11]. As a result, students with psychological inflexibility might display rigidity in their beliefs where they do not have sufficient resources to cope with these pressures. They might fixate on their stressful experience and fail to commit on behaviors that may be personally meaningful to achieve their valued goal. Eventually, this approach might take a huge toll on their mental health, thus increasing the odds of developing depression.

Findings also explained the substantial role of psychological inflexibility in the relationship between loneliness and depression. We cannot ascertain the relationship due the study being cross-sectional. Still, one reasonable interpretation is that students who have high psychological inflexibility may widen the discrepancies between reality and desired relationships, resulting in elevated feelings of loneliness and depression. Establishing a support system and close relationships with peers are crucial for students' transition in college [26], [29]. The school closures' and physical distancing regulation may be perceived as a hindrance, preventing them from developing close relationships with their peers, creating a feeling of loneliness. Their inability to accept the current situation or find an effective way to communicate are critical characteristics of psychological inflexibility [43]. It may prolong their feelings of loneliness and result in more severe mental health problems such as depression [28]-29]. 
In addition, we also identified sociodemographic variables that might pose as important factors associated with depression and psychological inflexibility. In line with previous findings [39], the increase in age was associated with lower depression and lower psychological inflexibility. Those with previous mental health records and had financial difficulties were also associated with higher depression and psychological inflexibility. As reported, extreme isolation due to virus or physical distancing may exacerbate preexisting psychological problems [60] and interrupted professional activities with no advanced planning [37]. Interestingly, our research found those who married, especially with children, were associated with lower depression and psychological inflexibility compared to the other group. The result contradicts previous literature studied in the U.K., which says psychological inflexibility and depression among single persons are lower than those in relationships [42]. These disparities could be due to cultural differences between Indonesia and the UK, where Indonesia adopted collectivist culture perceived family as the most important element of social support. The importance of family support during the COVID-19 pandemic was also explained in other studies [6]. Educational level was also associated with both variables, which is different from previous research [42]. However, the current study couldn't precisely ascertain the causal direction with correlational analysis; therefore, thorough future investigations are needed. Even so, these factors should be considered when dealing with college students' mental health. The exploration of sociodemographic factors may reveal which factor acts as a protective or risk role.

The findings should be interpreted within the following limitation. First, the use of convenience sampling and the imbalance in the number of participants for most sociodemographic categories may limit the generalizability of findings. Second, we collected all the data using online surveys and self-reported measures, which may be prone to bias from socially desirable attitudes. Third, present study used a crosssectional design; hence the association could be bidirectional as we cannot confirm a causal relationship among the variables. Experimental or longitudinal research could be an alternative to examine the causal between these variables more clearly. Fourth, due to the large sample size, relatively weak associations between sociodemographic factors and the main variables emerged as significant. These factors might have different results when tested in other populations; hence they must be explored further. Fifth, the use of global psychological inflexibility measures (AAQ-II) instead of dimensionspecific measures has limited the discussion of the relationship between variables. It is 
probably necessary to conduct further research using more comprehensive psychological inflexibility or various dimension-specific tools to identify the specific dimension to intervene.

Current findings have some important highlights for implications. As the COVID-19 outbreak is still ongoing and has not shown any signs of passing, perceived stress and loneliness have potentially become a common mental health problem during the pandemic. To our knowledge, our study is the first to examine the moderating role of psychological inflexibility in the relationship between perceived stress, loneliness, and depression in a college sample. Early identification of psychological inflexibility as a modifiable mechanism is key to preventing mental health problems from developing into depression symptoms. Reducing psychological inflexibility can help students accept their current difficulties during a pandemic and help them take meaningful action to finish their studies. The study encourages interventions that specifically target reducing psychological inflexibility, including Acceptance and Commitment Therapy or ACT [30]. ACT has shown promising results in treating psychological distress, including depression [30], [41], [61]. Findings also suggest the potential importance of sociodemographic factors to consider when applying intervention.

\subsection{Conclusion}

The current research showed psychological inflexibility as a potential contributor to mental health problems during the COVID-19 pandemic among Indonesian college students, such as perceived stress, loneliness, and depression. The study identified the role of psychological inflexibility as a significant moderator of perceived stress and Ioneliness toward depression. As this study also proved how numerous pandemics' impact on college students' mental health, identifying modifiable mechanisms for intervention targets such as psychological inflexibility will become very important for clinical or educational settings. Reducing psychological inflexibility might be one way to treat college students' depression during the pandemic. The right intervention targeting psychological inflexibility, such as ACT intervention, may help students to be more adaptive and mentally healthy during a difficult situation. These will also help prevent the development of more severe psychiatric problems. 
TABLE 1: Descriptive Data and Correlations between sociodemographic variables, depression, and psychological inflexibility ( $\mathrm{N}=941)$.

\begin{tabular}{|c|c|c|c|c|c|c|c|c|c|}
\hline \multirow[t]{2}{*}{ Variable } & \multirow[t]{2}{*}{ Total n (\%) } & \multirow[t]{2}{*}{$M(S D)$} & \multirow[t]{2}{*}{ Range } & \multicolumn{3}{|c|}{ Depression } & \multicolumn{3}{|c|}{ Psychological Inflexibility } \\
\hline & & & & r (Criteria) & $\mathrm{M}(\mathrm{SD})$ & Category & $r$ (Criteria) & $M(S D)$ & Category \\
\hline $\mathbf{A g e}^{a}$ & & 24 (4.89) & $18-39$ & $-.23^{* *}$ & & & $-.31^{* *}$ & & \\
\hline Gender $^{b}$ & & & & -.06 & & & $.17^{* *}$ & & \\
\hline Marital $^{b}$ & & & & $-.19^{* *}$ & & & $-.23^{* *}$ & & \\
\hline Single & 804 (85\%) & & & & $\begin{array}{l}9.82^{* * *} \\
(5.78)\end{array}$ & Mild & & $\begin{array}{l}29.77^{* * *} \\
(8.92)\end{array}$ & $\begin{array}{l}\text { Clinically } \\
\text { relevant }\end{array}$ \\
\hline Married & $62(6.1 \%)$ & & & & $\begin{array}{l}7.9^{* * *} \\
(5.19)\end{array}$ & Mild & & $\begin{array}{l}24.54^{* * *} \\
(9.47)\end{array}$ & Good \\
\hline $\begin{array}{l}\text { Married } \quad \text { w/ } \\
\text { Child }\end{array}$ & 70 (7\%) & & & & $\begin{array}{l}5.9^{* * *} \\
(4.87)\end{array}$ & Mild & & $\begin{array}{l}22.47^{* * *} \\
(8.5)\end{array}$ & Good \\
\hline Divorce & $5(0.1 \%)$ & & & & $\begin{array}{l}8.2^{* * *} \\
(5.26)\end{array}$ & Mild & & $\begin{array}{l}26.2^{* * *} \\
(9 . .57)\end{array}$ & Good \\
\hline $\begin{array}{l}\text { Previous } \\
\text { Mental Health } \\
\text { Record }^{b}\end{array}$ & & & & $.23^{* *}$ & & & $20^{* *}$ & & \\
\hline Yes & $68(7.2 \%)$ & & & & $\begin{array}{l}14.11^{* * *} \\
(6.06)\end{array}$ & $\begin{array}{l}\text { Moderately } \\
\text { Severe }\end{array}$ & & $\begin{array}{l}36.91^{* * *} \\
(7.87)\end{array}$ & $\begin{array}{l}\text { Clinically } \\
\text { relevant }\end{array}$ \\
\hline No & $512(54.4 \%)$ & & & 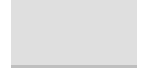 & $\begin{array}{l}7.13^{* * *} \\
(4.84)\end{array}$ & Mild & & $\begin{array}{l}25.22^{* * *} \\
(8.26)\end{array}$ & Good \\
\hline Maybe & 361 (38.4\%) & & & & $\begin{array}{l}11.71^{* * *} \\
(5.48)\end{array}$ & Moderate & & $\begin{array}{l}32.5^{* * *} \\
(8.24)\end{array}$ & $\begin{array}{l}\text { Clinically } \\
\text { relevant }\end{array}$ \\
\hline \multicolumn{10}{|l|}{$\begin{array}{l}\text { UNIVERSITY- } \\
\text { RELATED }\end{array}$} \\
\hline University $^{b}$ & & & & -.01 & & & $-.08^{*}$ & & \\
\hline $\begin{array}{l}\text { Education } \\
\text { Level }^{b}\end{array}$ & & & & $-.22^{* *}$ & . & & $-.29^{* *}$ & & \\
\hline Undergraduate & 487 (52\%) & & & & $\begin{array}{l}10.57^{* * *} \\
(.26)\end{array}$ & Moderate & & $\begin{array}{l}31.41^{* * *} \\
(8.95)\end{array}$ & $\begin{array}{l}\text { Clinically } \\
\text { relevant }\end{array}$ \\
\hline Master & 404 (43\%) & & & ( & $8.11^{* * *}(.27)$ & Mild & & $\begin{array}{l}26.3^{* * *} \\
(8.55)\end{array}$ & Good \\
\hline $\mathrm{PhD}$ & $50(5 \%)$ & & & & $\begin{array}{l}8.24^{* * *} \\
(.79)\end{array}$ & Mild & & $\begin{array}{l}24.72^{* * *} \\
(9.42)\end{array}$ & Good \\
\hline Field of Study $\mathbf{y}^{b}$ & & & & .03 & & & $.12^{*}$ & & \\
\hline \multicolumn{10}{|l|}{$\begin{array}{l}\text { COVID-19 } \\
\text { RELATED }\end{array}$} \\
\hline $\begin{array}{l}\text { Perceived } \\
\text { impact } \\
\text { covid-19 }\end{array}$ & & $\begin{array}{l}3.77 \\
(1.08)\end{array}$ & $0-5$ & $.21^{* *}$ (Small) & & & $.26^{* *}$ (Small) & & \\
\hline $\begin{array}{l}\text { Duration of } \\
\text { Impact }^{a}\end{array}$ & & $3.39(.76)$ & $0-6$ & .02 & & & .01 & & \\
\hline $\begin{array}{l}\text { Relative with } \\
\text { covid-19 }\end{array}$ & & & & -.06 & & & $-.06^{*}$ & & \\
\hline $\begin{array}{l}\text { Place of } \\
\text { Residence }^{b}\end{array}$ & & & & -.01 & & & $-.12^{* *}$ & & \\
\hline Income $^{b}$ & & & & $.10^{* *}$ & & & $.10^{* *}$ & & \\
\hline Yes & 761 (81\%) & & & & $\begin{array}{l}9.11^{* *} \\
(5.72)\end{array}$ & Mild & & $\begin{array}{l}28.38^{* *} \\
(9.24)\end{array}$ & $\begin{array}{l}\text { Clinically } \\
\text { relevant }\end{array}$ \\
\hline No & 180 (19\%) & & & & $\begin{array}{l}10.55^{* *} \\
(5.86)\end{array}$ & Moderate & & $\begin{array}{l}30.87^{* *} \\
(8.74)\end{array}$ & $\begin{array}{l}\text { Clinically } \\
\text { relevant }\end{array}$ \\
\hline $\begin{array}{l}\text { Financial } \\
\text { status }^{b}\end{array}$ & & & & $-13^{* *}$ & & & $-.11^{* *}$ & & \\
\hline Not enough & 124 (13.2\%) & & & & $\begin{array}{l}11.71^{* * *} \\
(5.72)\end{array}$ & Moderate & & $\begin{array}{l}32.19^{* * *} \\
(8.78)\end{array}$ & $\begin{array}{l}\text { Clinically } \\
\text { relevant }\end{array}$ \\
\hline Enough & 509 (54.1\%) & & & & $\begin{array}{l}9.15^{* * *} \\
(5.65)\end{array}$ & Mild & & $\begin{array}{l}28.57^{* * *} \\
(9.02)\end{array}$ & $\begin{array}{l}\text { Clinically } \\
\text { relevant }\end{array}$ \\
\hline $\begin{array}{l}\text { More than } \\
\text { enough }\end{array}$ & $\begin{array}{l}308 \\
(32.7 \%)\end{array}$ & & & & $\begin{array}{l}8.85^{* * *} \\
(5.78)\end{array}$ & Mild & & $\begin{array}{l}27.99^{* * *} \\
(9.36)\end{array}$ & $\begin{array}{l}\text { Clinically } \\
\text { relevant }\end{array}$ \\
\hline
\end{tabular}


TABLE 2: Descriptive statistics and correlations among primary variables

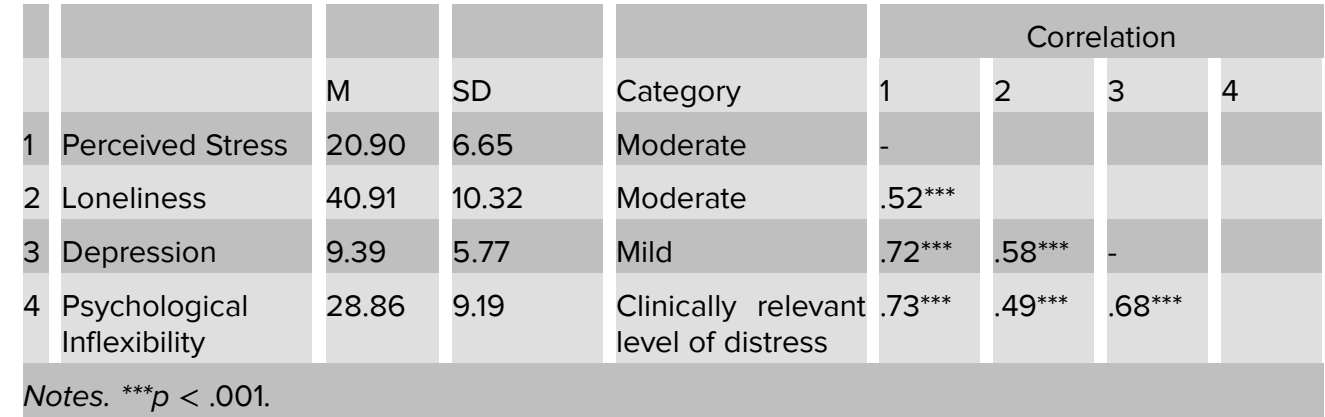

\section{Acknowledgments, Funding, \& Ethics Policies}

A. M. Radyani, G. H. Indra, and I. I. D. Oriza developed the study concept. A.M. Radyani designed, analyzed, interpreted, and drafted the manuscript of the study. A. M. Radyani and G. H. Indra collected the data. I. I. D. Oriza provided assistance and critical revisions. All authors approved the final manuscript for publication. The study was funded by the Indonesia Endowment Fund for Education (LPDP) from the Ministry of Finance of the Republic of Indonesia in the form of scholarship. The funder had no role in the design, conduct of the study, or approval of the manuscript publication. The research had been approved by the ethics committee of the associated university. All participants had been informed about the purpose and details of the study and had signed informed consent prior to participating in the study.

\section{References}

[1] World Health Organization. WHO coronavirus disease (COVID-19) dashboard. 2020. Cite at 21 Dec 2021. Available from: https://covid19.who.int

[2] Chakraborty I, Maity, P. COVID-19 outbreak: Migration, effects on society, global environment and prevention. Science of the Total Environment. 2020;728:138882. https://doi.org/10.1016/j.scitotenv.2020.138882

[3] Cao W, Fang Z, Hou G, Han M, Xu X, Dong J. The psychological impact of the COVID19 epidemic on college students in China. Psychiatry Research. 2020;287(May 2020)112934. https://doi.org/https://doi.org/10.1016/j.psychres.2020.112934

[4] Xiao C. A novel approach of consultation on 2019 novel coronavirus (COVID-19)related psychological and mental problems: Structured letter therapy. Psychiatry Investigation. 2020;17(2):175-176. https://doi.org/10.30773/pi.2020.0047

[5] Pierce M, Hope H, Ford T, et al. Mental health before and during the COVID-19 pandemic: A longitudinal probability sample survey of the UK population. The Lancet 
Psychiatry. 2020;7(10):883-892. https://doi.org/10.1016/S2215-0366(20)30308-4

[6] Liu CH, Zhang E, Wong GTF, Hyun S, Hahm HC. Factors associated with depression, anxiety, and PTSD symptomatology during the COVID-19 pandemic: Clinical implications for U.S. young adult mental health. Psychiatry Research. 2020;290:113172. https://doi.org/10.1016/j.psychres.2020.113172

[7] Bruffaerts R, Mortier P, Kiekens G, et al. Mental health problems in college freshmen: Prevalence and academic functioning. Journal of Affective Disorders. 2018;225(December 2016):97-103. https://doi.org/10.1016/j.jad.2017.07.044

[8] Arnett JJ. Emerging adulthood: A theory of development from the late teens through the twenties. American Psychologist. 2000;55(5):469-480. https://doi.org/10.1037/0003-066X.55.5.469

[9] Pedrelli P, Nyer M, Yeung A, Zulauf C, Wilens T. College students: Mental health problems and treatment considerations. Academic Psychiatry. 2015;39(5):503-511. https://doi.org/10.1007/s40596-014-0205-9

[10] Tavakoli N, Broyles A, Reid EK, Sandoval JR, Correa-Fernández V. Psychological inflexibility as it relates to stress, worry, generalized anxiety, and somatization in an ethnically diverse sample of college students. Journal of Contextual Behavioral Science. 2019;11(May):1-5. https://doi.org/10.1016/j.jcbs.2018.11.001

[11] Zhang M, Zhang J, Zhang F, Zhang L, Feng D. Prevalence of psychological distress and the effects of resilience and perceived social support among Chinese college students: Does gender make a difference? Psychiatry Research. 2018;267( June):409-413. https://doi.org/10.1016/j.psychres.2018.06.038

[12] Conrad R, Rayala H, Menon M, Vora K. Universities' response to supporting mental health of college students during the COVID-19 pandemic. Psychiatric Times. 23 March 2020. Cite 21 Dec 2021 Available from: https://www.psychiatrictimes.com/view/universities-response-supporting-mentalhealth-college-students-during-covid-19-pandemic

[13] Huckins JF, daSilva AW, Wang W, et al. Mental health and behavior of college students during the early phases of the COVID-19 pandemic: Longitudinal smartphone and ecological momentary assessment study. Journal of Medical Internet Research. 2020;22(6):e20185. https://doi.org/10.2196/20185

[14] Bu F, Steptoe A, Fancourt D. Who is lonely in lockdown? Cross-cohort analyses of predictors of loneliness before and during the COVID-19 pandemic. 2020;186. https://doi.org/10.1101/2020.05.14.20101360

[15] Wang ZH, Yang HL, Yang YQ, et al. Prevalence of anxiety and depression symptom, and the demands for psychological knowledge and interventions in college students 
during COVID-19 epidemic: A large cross-sectional study. Journal of Affective Disorders. 2020;275(1023):188-193. https://doi.org/10.1016/j.jad.2020.06.034

[16] Pakenham KI, Landi G, Boccolini G, Furlani A, Grandi S, Tossani E. The moderating roles of psychological flexibility and inflexibility on the mental health impacts of COVID-19 pandemic and lockdown in Italy. Journal of Contextual Behavioral Science. 2020;17( July):109-118. https://doi.org/10.1016/j.jcbs.2020.07.003

[17] Chirikov I, Soria KM, Horgos B, Jones-White, D. Undergraduate and graduate students' mental health during the COVID-19 pandemic. 2020. 202008-17. UC Berkeley: Center for Studies in Higher Education. Retrieved from https://escholarship.org/uc/item/80k5d5hw

[18] Evans TM, Bira L, Gastelum, JB, Weiss LT, Vanderford NL. Evidence for a mental health crisis in graduate education. Nature Biotechnology. 2018;36(3):282-284. https://doi.org/10.1038/nbt.4089

[19] Levecque K, Anseel F, De Beuckelaer A, Van der Heyden J, Gisle L. Work organization and mental health problems in PhD students. Research Policy. 2017;46(4):868-879. https://doi.org/10.1016/j.respol.2017.02.008

[20] Stay home, President says. The Jakarta Post. 2020 March 16. Available from: https://www.thejakartapost.com/news/2020/03/16/stay-home-president-says.html

[21] Indonesian Psychiatric Association. 5 bulan pandemi COVID-19 di Indonesia. PDSKJI.org. 2020 August 4. Available from: http://pdskji.org/home

[22] UNICEF. Young people take the lead on mental health. 2020 August 28. Available from: https://www.unicef.org/indonesia/coronavirus/stories/young-people-take-leadmental-health

[23] Tull MT, Edmonds KA, Scamaldo KM, Richmond JR, Rose JP, Gratz KL. Psychological outcomes associated with stay-at-home orders and the perceived impact of COVID-19 on daily life. Psychiatry Research. 2020;289(April):113098. https://doi.org/10.1016/j.psychres.2020.113098

[24] World Health Organization. Depression. [Date Unknown]. Available from: https://www.who.int/health-topics/depression\#tab=tab_1

[25] Cacioppo JT, Hughes ME, Waite LJ, Hawkley LC, Thisted RA. Loneliness as a specific risk factor for depressive symptoms: Cross-sectional and longitudinal analyses. Psychology and Aging. 2006;21(1):140-151. https://doi.org/10.1037/0882-7974.21.1.140

[26] Richardson T, Elliott P, Roberts R. Relationship between loneliness and mental health in students. Journal of Public Mental Health. 2017;16(2):48-54. https://doi.org/10.1108/JPMH-03-2016-0013 
[27] Alaviani M, Parvan R, Karimi F, Safiri S, Mahdavi N. Prevalence of loneliness and associated factors among Iranian college students during 2015. Journal of Archives in Military Medicine. 2017;5(1). https://doi.org/10.5812/jamm.42356

[28] Moeller RW, Seehuus M. Loneliness as a mediator for college students' social skills and experiences of depression and anxiety. Journal of Adolescence. 2019;73(March):1-13. https://doi.org/10.1016/j.adolescence.2019.03.006

[29] Thomas L, Orme E, Kerrigan F. Student loneliness: The role of social media through life transitions. Computers and Education. 2020;146(September):103754. https://doi.org/10.1016/j.compedu.2019.103754

[30] Hayes SC, Strosahl KD, Wilson KG. Acceptance and commitment therapy: The process and practice of mindful change. $2^{\text {nd }}$ ed. 2012. New York: The Guilford Press

[31] Cohen S, Kamarck T, Mermelstein R. A global measure of perceived stress. Journal of Health and Social Behavior. 1983;24(4):385-396.

[32] Cristóbal-Narváez P, Haro JM, Koyanagi A. Perceived stress and depression in 45 low- and middle-income countries. Journal of Affective Disorders. 2020;274(April):799-805. https://doi.org/10.1016/j.jad.2020.04.020

[33] Kuiper NA, Olinger LJ, Lyons LM. Global perceived stress level as a moderator of the relationship between negative life events and depression. Journal of Human Stress. 1986;12(4):149-153. https://doi.org/10.1080/0097840X.1986.9936781

[34] Pedrelli P, Feldman GC, Vorono S, Fava M, Petersen T. Dysfunctional attitudes and perceived stress predict depressive symptoms severity following antidepressant treatment in patients with chronic depression. Psychiatry Research. 2008;161(3):302308. https://doi.org/10.1016/j.psychres.2007.08.004

[35] Lazarus RS. Psychological stress and the coping process. The American Journal of Psychology. 1966;83(4):634-637. https://doi.org/https://doi.org/10.2307/1420698

[36] Peplau LA, Perlman D. Loneliness: A sourcebook of current theory, research, and therapy. New Jersey: Wiley; 1982.

[37] Brooks SK, Webster RK, Smith LE, et al. The psychological impact of quarantine and how to reduce it: Rapid review of the evidence. The Lancet. 2020;395(10227):912920. https://doi.org/10.1016/S0140-6736(20)30460-8

[38] Davis AK, Barrett FS, Griffiths RR. Psychological flexibility mediates the relations between acute psychedelic effects and subjective decreases in depression and anxiety. Journal of Contextual Behavioral Science. 2020;15(April 2019):39-45. https://doi.org/10.1016/j.jcbs.2019.11.004 
[39] Dawson DL, Golijani-Moghaddam N. COVID-19: Psychological flexibility, coping, mental health, and wellbeing in the UK during the pandemic. Journal of Contextual Behavioral Science. 2020. https://doi.org/https://doi.org/10.1016/j.jcbs.2020.07.010

[40] Kroska EB, Roche Al, Adamowicz JL, Stegall MS. Psychological flexbility in the context of COVID-19 adversity: Associations with distress. Journal of Contextual Behavioral Science. 2020. https://doi.org/10.1016/j.progpolymsci.2020.101219

[41] Kashdan TB, Rottenberg J. Psychological flexibility as a fundamental aspect of health. Clinical Psychology Review. 2010;30(4):865-878. https://doi.org/10.1016/j.cpr.2010.03.001

[42] Tyndall I, Waldeck D, Pancani L, Whelan R, Roche B, Pereira A. Profiles of psychological flexibility. Behavior Modification. 2020;44(3):365-393. https://doi.org/oOr.g1/107.171/0771/405145445451581882200036

[43] Bond FW, Hayes SC, Baer RA, et al. Preliminary psychometric properties of the acceptance and action questionnaire-ll: A revised measure of psychological inflexibility and experiential avoidance. Behavior Therapy. 2011;42(4):676-688. https://doi.org/10.1016/j.beth.2011.03.007

[44] Eisenbeck N, Carreno DF, Uclés-Juárez R. From psychological distress to academic procrastination: Exploring the role of psychological inflexibility. Journal of Contextual Behavioral Science. 2019;13(February):103-108. https://doi.org/10.1016/j.jcbs.2019.07.007

[45] kashdan ME, MacLane C, Daflos S, et al. Examining psychological inflexibility as a transdiagnostic process across psychological disorders. Journal of Contextual Behavioral Science. 2014;3(3):155-163. https://doi.org/10.1016/j.jcbs.2014.06.003

[46] Schramm AT, Pandya K, Fairchild AJ, Venta AC, de Roon-Cassini TA, Sharp C. Decreases in psychological inflexibility predict PTSD symptom improvement in inpatient adolescents. Journal of Contextual Behavioral Science. 2020;17( June):102108. https://doi.org/10.1016/j.jcbs.2020.06.007

[47] Crasta D, Daks JS, Rogge RD. Modeling suicide risk among parents during the COVID-19 pandemic: Psychological inflexibility exacerbates the impact of COVID-19 stressors on interpersonal risk factors for suicide. Journal of Contextual Behavioral Science. 2020;18(August):117-127. https://doi.org/10.1016/j.jcbs.2020.09.003

[48] Hayes SC, Luoma JB, Bond FW, Masuda A, Lillis J. Acceptance and commitment therapy: model, processes and outcomes. Behaviour Research and Therapy. 2006;44(1):1-25. https://doi.org/10.1016/j.brat.2005.06.006

[49] Peltz JS, Rogge RD, Bodenlos JS, Kingery JN, Pigeon WR. Changes in psychological inflexibility as a potential mediator of longitudinal links between college students' 
sleep problems and depressive symptoms. Journal of Contextual Behavioral Science. 2020;15( July):110-122. https://doi.org/10.1016/j.jcbs.2019.12.003

[50] Jeffords JR, Bayly BL, Bumpus MF, Hill LG. Investigating the relationship between university students' psychological flexibility and college self-efficacy. Journal of College Student Retention: Research, Theory \& Practice. 2020;22(2):351-372. https://doi.org/10.1177/1521025117751071

[51] Hary ZAP. Hubungan antara kelekatan terhadap ibu dengan tingkat stres pada mahasiswa perantau [Undergraduate thesis].Jakarta: Sanata Dharma University; 2017.

[52] Russell D. UCLA Loneliness Scale Version 3 (Instructions). Journal of Personality Assessment. 1996;66(42):3-4. https://doi.org/10.1207/s15327752jpa6601

[53] Russell D, Peplau LA, Cutrona CE. The revised UCLA Loneliness Scale: Concurrent and discriminant validity evidence. Journal of Personality and Social Psychology. 1980;39(3):472-480. https://doi.org/10.1037/0022-3514.39.3.472

[54] Jaya ES, Arjadi R, Ayuningtyas AUH, Utoyo DB. Investigation in the validity and reliability of the Indonesian UCLA loneliness scale. 22nd International Congress IACCP. 2014. https://doi.org/10.1207/s15327752jpa6601

[55] Permadi D, Nurwianti F. Mindfulness and coping skills as predictors of competitive anxiety amongst athletes in Indonesia. ANIMA Indonesian Psychological Journal. 2019;33(4):231-240. https://doi.org/10.24123/aipj.v33i4.1796

[56] Kroenke K, Spitzer RL, Williams JBW. The PHQ-9: Validity of a brief depression severity measure. Journal of General Internal Medicine. 2001;16(9):606-613. https://doi.org/10.1046/j.1525-1497.2001.016009606.x

[57] Hayes AF. Introduction to mediation, moderation, and conditional process analysis: A regression-based approach. Kenny DA, Little TD, editors. New York: The Guilford Press; 2018.

[58] Kelley K, Preacher KJ. On effect size. Psychological Methods. 2012;17(2):137-152. https://doi.org/10.1037/a0028086

[59] Kashdan TB, Kane JQ. Post-traumatic distress and the presence of post-traumatic growth and meaning in life: Experiential avoidance as a moderator. Personality and Individual Differences. 2011;50(1):84-89. https://doi.org/10.1016/j.paid.2010.08.028

[60] Inchausti F, MacBeth A, Hasson-Ohayon I, Dimaggio G. Psychological intervention and COVID-19: What we know so far and what we can do. Journal of Contemporary Psychotherapy. 2020;50(4):243-250. https://doi.org/10.1007/s10879-020-09460-w

[61] Levin ME, Krafft J, Twohig MP. Examining processes of change in an online acceptance and commitment therapy dismantling trial with distressed 
college students. Journal of Contextual Behavioral Science. 2020;17(April):10-16. https://doi.org/10.1016/j.jcbs.2020.05.001

[62] Xiao H, Carney DM, Youn SJ, et al. Are we in crisis? National mental health and treatment trends in college counseling centers. Psychological Services. 2017;14(4):407-415. https://doi.org/http://dx.doi.org/10.1037/ser0000130 